\title{
Hybrid Carbon/Glass Fiber Reinforced Polymer; A Frontier Material for Aerospace Industry : A Review on Mechanical Properties Enhancement
}

\author{
Ahmad Fuad Ab Ghani1 ${ }^{1,}$, NorAzazi Ngatiman ${ }^{1}$, Ridhwan Jumaidin ${ }^{1}$, Sivakumar A/L Dharmalingam² Fudhail Abdul Munir ${ }^{2}$, and Rahifa \\ Ranom $^{3}$ \\ ${ }^{1}$ Faculty of Engineering Technology Mechanical and Manufacturing (FTKMP), Universiti Teknikal Malaysia Melaka (UTeM),Hang Tuah Jaya, 75450 , \\ Melaka, MALAYSIA \\ ${ }^{2}$ Faculty of Mechanical Engineering (FKM), Universiti Teknikal Malaysia Melaka (UTeM),Hang Tuah Jaya, 75450, Melaka, MALAYSIA \\ ${ }^{3}$ Faculty of Electrical Engineering (FKE), Universiti Teknikal Malaysia Melaka (UTeM), Hang Tuah Jaya, 75450, Melaka, MALAYSIA
}

\begin{abstract}
Composite is the combination of two or more materials that differ in properties and composition to form unique properties. This paper reported the deformation of hybrid composite under tensile, shear and flexural loading. This review provides insight and state of the art for mechanics of composites that provides underlying theory for understanding the deformation and behaviour for the hybrid composite under various loading conditions. This paper also discusses mechanical behaviour of hybrid composites under static loading (Tensile, Shear, Flexural). It is essential to understand the principle that governs the mechanics of composites of laminate under loading which also applicable to hybrid composites C/GFRP.The high modulus fibre, such as Carbon fibre offers stiffness and load bearing capabilities, whereas the low modulus fibre, such as glass fibre makes the composite more durable and low in cost.
\end{abstract}

ARTICLE HISTORY

Received: $15^{\text {th }}$ Sept 2021

Revised: $28^{\text {th }}$ Oct 2021

Accepted: $17^{\text {th }}$ Nov 2021

KEYWORDS

Carbon Glass Fibre

Reinforced

Hybrid Composite

Mechanical Properties

Shear

Flexural

\section{INTRODUCTION}

Composite is the combination of two or more materials that differ in properties and composition to form unique properties. Normally, composite increase of the durability or strength over many other materials at the same time may provide additional benefits such as resistance corrosion [1]. Fibre reinforced plastic (FRP) is a type of composite material produced by polymer matrix reinforced with fibres. Composite materials become a popular choice compared to the traditional materials due to their mechanical properties such as high strength and stiffness that are beneficial to application in the marine, automotive and aerospace industries [2]. Glass, carbon, graphite, and aramid fibres have been widely used, based on their applications although other materials are also available such as kevlar and wood. The availability of various composite materials ensures that range of FRP materials are used for many structural applications as shown in Figure 1. It depicts the practical application of GFRP and CFRP under the segment of the combination plastics and ceramics \& glasses. The high strength to weight ratio of the FRP materials may be customized in order to design optimal structures compared to traditional structures which made using metal alloys [3].

\section{HYBRID COMPOSITES CARBON/GLASS FIBRE REINFORCED POLYMER (C/GFRP)}

Hybrid composites are formed by more than two different fibres incorporate into a type of matrix to provide specific performance attributes. Hybrid composites are often made by combining the high and low modulus fibres. Nevertheless, the optimum arrangement between these fibres is still under comprehensive investigation. 


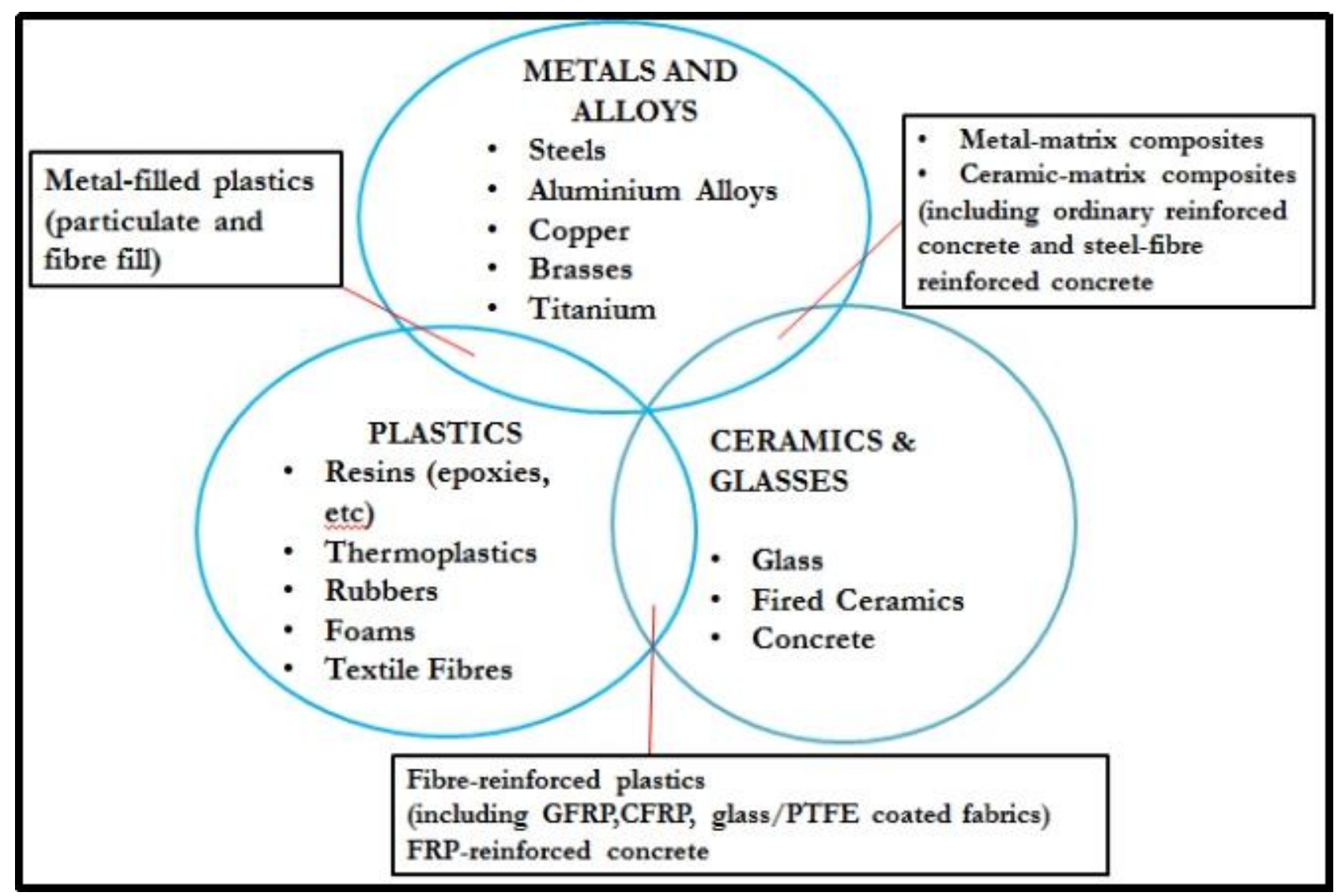

Figure 1. Positioning Of Classes Of Engineering Materials Showing The Advancement Of Composites [1]

Compared to conventional fibre reinforced polymer (FRP) such as Carbon Fibre Reinforced Polymer (CFRP) and Glass Fibre Reinforced Polymer (GFRP), hybrid composite materials improved the mechanical properties by work together for even stronger performance. Generally, hybrid composite consists of more than one reinforcing sections or multiple reinforcing or multiple matrix section or single reinforcing phase with multiple matrix phase. As a result of compromise between the materials within the hybrid composite, the deformation and stress analysis are to be evaluated and tailored as each constituent of material carry their own desired mechanical properties according to performance requirement [4]. As the hybrid composite continued to gain the popularity, the research study regarding the mechanical properties and performance of hybrid composite with latest input could be the parameters for composite designer, engineers and practitioners to optimize hybrid composite performance for their latest development of structural components. Even though in general principle of hybrid composite that the multiple types of fibre may be incorporated into a matrix, however the synergy of two types of fibre would be the most practical and less complex process involved [1]. Hybrid composite evolved as an innovation and alternative to conventional composite which consist only one type of fibre. Hybrid composites which made up of several different components claimed to have special features that can be designed to specific conditions for endless design possibilities in more economical way comparing with the conventional composite.

Mechanical properties play important role in determining between stiff and strong materials from mechanical deformation and behavioral perspective; whether static or dynamic loading and uniaxial or multi axial loading. The interesting question always queried among researchers and industrial practitioners as how does the deformation of hybrid composite under static loading differ from conventional composite. As the properties of glass fibre having lower tensile modulus and higher failure to strain as compared to carbon fibre, glass fibre acts as improvement to the hybrid composite structure. The tensile properties such as tensile modulus in longitudinal/transverse direction, tensile strength in longitudinal/transverse direction, failure strain in longitudinal/transverse direction are more important to take into account together with cost saving [5]. The properties such as fibre content, orientation, dimension of constituent fibres (diameter), level of intermixing of fibres, interface bonding between fibre and matrix, and arrangement of fibres between different types of fibres, influences the mechanical properties of hybrid composite whereas the strength of hybrid composite relies on failure strains of each fibres where higher failure strain on one type of fibre could satisfy the others [4],[6]. The modulus of elasticity and improved tensile strength of hybrid composite could bring the greater impact on the application in industry such as aerospace, automotive, marine etc. The fact that tensile strength of the hybrid composite lies between solid CFRP and solid GFRP because of the mechanical properties of GFRP bring the improvement to the modulus of elasticity and tensile strength of hybrid composite [7]. Advantages of hybrid composite can be seen in terms of improved stiffness and strength, enhanced bending properties, improvement of distortion stability, reduced weight and cost, improved fatigue resistance, decrement of notch sensitivity, better fracture toughness and crack arresting abilities as well 
as resistance to impact [8],[9]. Hybrid composites can be considered among best options in materials design which in some circumstances single constituent fibre composites could not meet required specifications. Hence various aspects must be taken into consideration for a given structural composite design which incorporates modulus of elasticity, strain to failure, strength, damage behaviour, impact characterization and dynamic loading, manufacturing, density etc [10].

Carbon fibre which possesses low elongation at break (approximately about 2\%), leads to the brittle fracture of its composites. Hybridization from the use of two or more types of fibres reinforced the same resin, the disadvantages of one type fibres can be trade off by the advantages of the others [5]. It also provides synergetic increase of the failure strain of low elongation fibres when hybridised with higher elongation fibres. Meaning that the Carbon Fibre has a very low strain to failure and regarded as a disadvantage when utilized as structural members that are subjected to tensile, compressive, shear and or/flexural loading. On the other hand, glass fibres which have much lower strength than carbon fibres but are much tougher due to having a higher strain-to-failure. It has been proved that incorporation of GF into CF is possible with a view to improve the failure strain of CFRP, turning the materials to a combination system called hybrids [11],[12]. Apart from the toughness issue, CF are also very expensive which is regarded as the main drawback why CFRP are only popular in aero industries and automotive sector where weight saving is considered to be the primary concern [12]. GF are cheaper than CF and the glass fibre reinforced polymers (GFRP) have been increasingly utilized to substitute steel in automotive industry. Hybridization of GF into CF selectively could be an effective means to reduce vehicle weight without implying high cost [13].

\section{CHALLENGES IN DESIGNING HYBRID COMPOSITE C/GFRP}

Although the innovative fibre hybridization has been around for quite some time [14 ], [15 ] a recent frontier of new materials creates new and exciting possibilities for obtaining superior hybrid composites tailored for particular applications. In order to achieve both design adaptability and reduction of cost, there is a need to develop the carbon/glass hybrid composite and evaluate its mechanical properties. This is a major challenge that can only be met through an understanding of the relationships between materials architecture and mechanical response, as well as observing microstructure formation. Problems arise, however, when attempts are made to predict processes of failure. The failure of composites is almost always a complex process [16]-[18]. Damage accumulates in a widespread fashion in composites, and many individual processes occur at the micro structural level [19],[20]. Apart from that, there are debates on whether hybridization of CFRP/GFRP exhibits unique deformation for distinct layups of Unidirectional [21], Balanced Crossply [22], Quasi Isotropic [23] under tensile, flexural loading and their failure modes. The general finding was that quasi-UD composites exhibit nonlinear stress-strain behavior when they were subjected to transverse loading [17]. Strength is more difficult to predict than elastic properties because it depends on the mechanisms of damage accumulation and failure as well as on the properties of the constituents [24],[25]. Digital image correlation methods (DIC) first been developed in the early 1980s has influenced positively in the field of mechanics of solids and structures and it is still experiencing interesting developments [26]-[28]. The idea is to measure the displacement fields of surfaces of stressed specimens and structures from images acquired at different stages of loading. A specific advantage of this tool is that it exploits numerical images that usually acquired by optical means. More generally, full-field measurements constitute an opportunity to bridge the gap between experiments and simulations allowing for direct displacement and strain comparisons [27],[29],[30].

\section{MECHANICS OF HYBRID COMPOSITE C/GFRP}

In The stress-strain relationship is an essential principle for mechanics of composite study. Material under study; CFRP and GFRP are both unidirectional (UD) composites which possess orthotropic material properties which have different elasticity deformation behavior at longitudinal and transversal direction with respect to fibre orientation. For an orthotropic system, the stress strain relationship is given as follow [31],[32]:

$$
\sigma_{1}=E_{1} \varepsilon_{1} \text { and } \sigma_{2}=E_{2} \varepsilon_{1}
$$

the relation between the stress and strain in terms of the compliance matrix and the stiffness matrix are given as follows [31], [34 ]:

$$
\left[\begin{array}{c}
\sigma_{1} \\
\sigma_{2} \\
\tau_{12}
\end{array}\right]=\left[\begin{array}{ccc}
Q_{11} & Q_{12} & 0 \\
Q_{12} & Q_{22} & 0 \\
0 & 0 & Q_{66}
\end{array}\right]\left[\begin{array}{c}
\varepsilon_{1} \\
\varepsilon_{2} \\
\gamma_{12}
\end{array}\right]
$$


where matrix is the compliance matrix and [Q] is the stiffness matrix. If the lamina is loaded at some angle other than $0^{\circ}$ or $90^{\circ}$, the stresses and strains will not be the same since they are vectors and therefore a relation needs to be derived which considers the general angle at which the lamina is oriented. The constitutive equations that relate to stress and strain behavior of composite laminate are based on Composite Laminate Theory. This relation gives understanding on behavior with respect to extension, bending and coupling of composite laminate [31],[34].

\section{Carbon and Glass Fibre Reinforced Polymer Characteristics}

Proper selection of the fiber type is very important, since it influences the characteristics of a composite laminate. Accordingly, in this review two types of fibers have been study. These are E-glass fiber and carbon fiber. E-glass has the lowest cost of all commercially available reinforcing fibers, which is the reason for its widespread use in the FRP industry. In an example, there was a study in construction industry where the use of carbon fibers and glass fibers were combined to strengthen concrete flexural members. It is observed that when carbon and glass fibers are hybridized, an ultimate strain at the first fiber (carbon) rupture even higher than the ultimate strain of the second fiber (glass only) [35]. Swolf et al [36] discovered that some current trends in fibre hybridisation, such as pseudo-ductility, ductile fibres and natural fibre hybrids, are anticipated to play major role in the new developments of hybrid composites. An experimental investigation was performed to determine the effective mechanical properties of the flanges and web of the hybrid FRP composite girder [37]. The innovative feature of this composite girder enhances the combined use of carbon fibre reinforced polymer (CFRP) and glass fibre reinforced polymer (GFRP) for maximum structural performance while decreasing the construction cost [37].

\section{Carbon Fibre Reinforced Polymer (CFRP)}

Carbon fibre is made of carbon crystals aligned in a longitudinal axis. It is a lightweight and yet strong material compared to steel, and weighs about one-tenth of conventional steel [1]. The properties of carbon fibres include high stiffness, high tensile strength, least weight, high resistance towards chemicals, high tolerance on temperature and low thermal expansion. It possesses a high modulus because of the highly graphitized structure of pitch-based carbon fibres [38]. It is commercially used in aerospace, civil engineering, and motorsports industries. However, it is relatively expensive compared to the other fibres, such as glass fibre. Rahmani et al [39] studied the T700 CFRP as used in aerospace industry on its elastic properties with fabrication of some laminated samples with cross-ply configuration. They found that tensile properties influenctial factor of the laminated composites were the fibre orientations. In other work, Bitkina et al , [40] performed on experimental of the effect of disorientation angle on the deformation of carbon composite plates. These results are applicable to industrial scenario because eight-layer carbon composite structures have various applications such as aviation, wind turbine, aerospace, etc. It is found that by increasing of disorientation angle has increased the deformation of the composite structures, because that disorientation angle affects the symmetry of the composite layered structure.

\section{Glass Fibre Reinforced Polymer (GFRP)}

Glass fibre is the most commonly used composite in the composites industry. E-glass, $\mathrm{S}$ glass, $\mathrm{R}$ glass and $\mathrm{Z}$ glass are the varieties of glass fibre used in composite. The presence of GFRP polymer matrix produces an attractive combination of physical and mechanical properties that cannot be obtained by monolithic based materials [41]. GFRP is a strong lightweight material which can be moulded into complex shapes that can be used in many products. Although it is not as strong and stiff as CFRP, it is less brittle and cheaper [1]. Hybrid composites for this study comprises of Carbon Fibre Reinforced Polymer (CFRP) which possesses high-modulus fibre, high strength and high cost with Glass Fibre Reinforced Polymer (GFRP) which associated with low modulus, slightly lower tensile strength, higher flexural strength and low cost [42]. In a study on in-plane shear properties of cross-ply laminates with different off-axis angles, the mechanical, dynamics, tribological and thermal properties of GFRP composites have been discussed [43]. It is obtained that, modulus of elasticity of the composite increased with the fiber glass Vf, volume fraction. Ultimate tensile strength and flexural strength of the fiber glass polyester composite increased with increase in the fiber glass Vf, volume fraction [44]. A unidirectional (UD) fabric is one in which the majority of fibres run in one direction only. The main intention is being to hold the primary fibres in position, although the other fibres may also offer some structural properties. This results in the highest possible fibre properties from a fabric in composite component construction for loading at fibre the principal direction i.e. 0o [45]. The in-plane shear characterization has been carried out on carbon fibre reinforced unidirectional laminate with several fibre orientation angles: $10^{\circ}, 20^{\circ}, 30^{\circ}$, and $45^{\circ}$ [25], [46], [47]. The basic working principles are to utilize $0^{\circ}$ prepreg for bending stiffness and $\pm 45^{\circ}$ prepreg for torsional stiffness and anything in between depending on the desired combination. 
A number of literatures been reviewed on tensile behavior of the hybrid composite under static loading. In one study, the tensile and compressive loading tests on hybrid glass/carbon fabric composites have been performed and the important observation was that by positioning glass fabric layers in the exterior layup and carbon fabric layers in the interior, higher tensile strength and ultimate tensile strain were obtained [9]. It is found that even though carbon fibre reinforced polymer and glass fibre reinforced polymer are quasi brittle materials, they can exhibit pseudo ductility when they are hybridised in a practical way [36]. A preliminary study on the performance and their comparison of hybrid and the non-hybrid composite were reported in [48]. It was reported that the tensile properties of the hybrid composite fall in between nonhybrid (baseline) composite properties. Among the hybrid composites tested, the filament wound composites demonstrated marginally better tensile strength and stiffness as compared to hybrid fabrics as shown in Figure 2 . The authors opined that optimizing fibre architecture and its parameters are important for developing new hybrid fabrics for composite product developments [48]. This is due to the fact that, filament winding involves the use of very long continuous fibers. This improves strength of the composite whereby discontinuities in the fibers will not transfer load as well [49]. High modulus is attained due to intermittent control of fiber angle [50]. It relates to this study where quasi isotropic layup of hybrid composites with significant $\pm 45^{\circ}$ layup similar to filament winding orientation that is expected to possess much higher mechanical properties than balanced crossply hybrid composite.

\section{Tensile Behavior of Hybrid C/CFRP}

This chart showed the comparisons of hybrid and Non-hybrid Stiffness.

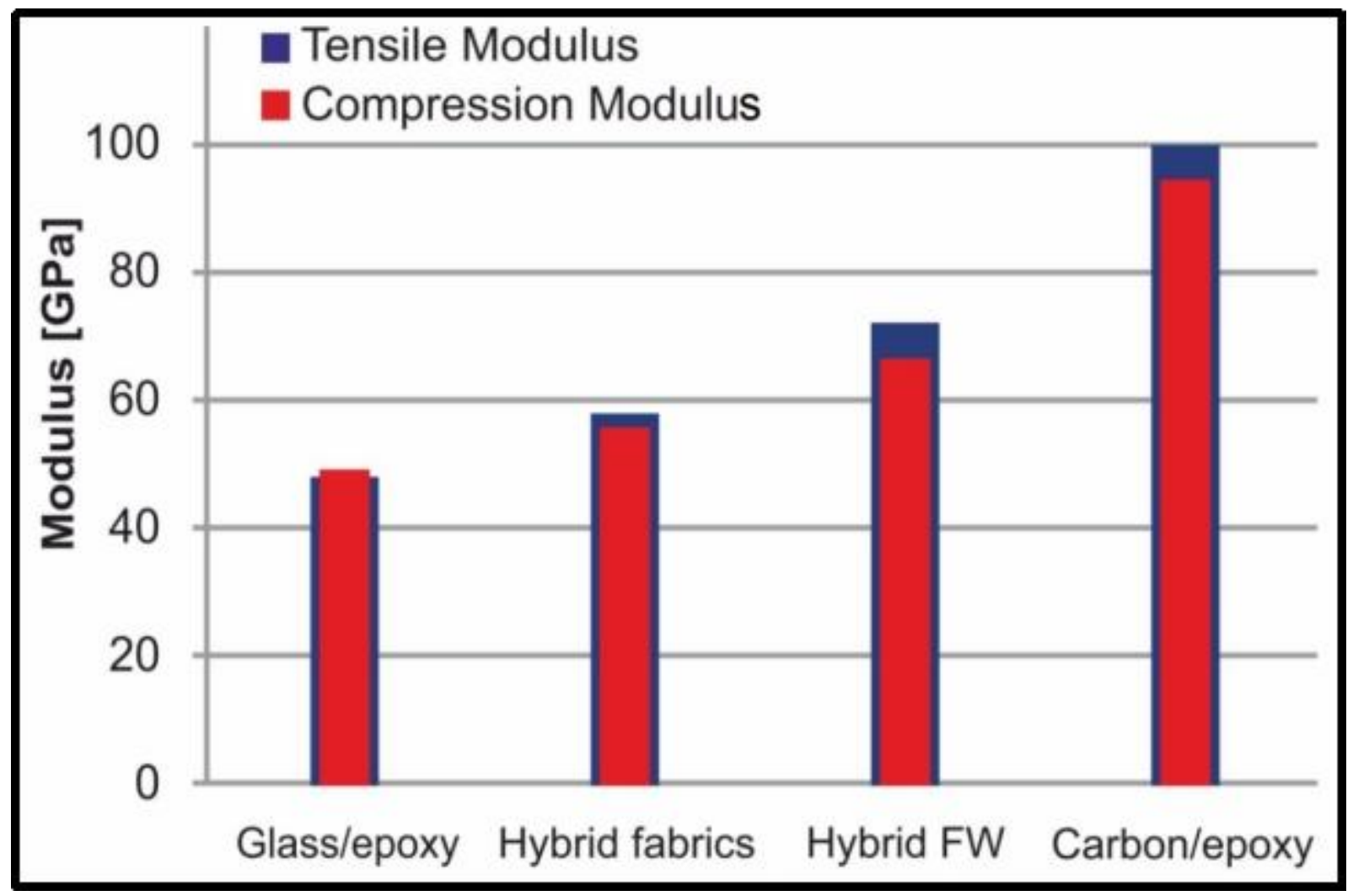

Figure 2. The Comparisons of Hybrid and Non Hybrid Stiffness [48]

Irina et al (2015), studied on three different types of hybrid arrangement of carbon fibre and E glass fibre were experimentally tested: $[\mathrm{CWW}] 6,[\mathrm{BC}] 6$, and $[\mathrm{CBBC}] 3$, where $\mathrm{C}, \mathrm{W}$, and $\mathrm{B}$ denotes carbon fibre, $\mathrm{E}$ glass plain woven and E glass stitch biaxial $\left( \pm 45^{\circ}\right)$, respectively. Tensile test showed that the [CWCW]6 arrangement, which $\mathrm{C}$ and W formed by weaved carbon fibre and glass fibre provided the best mechanical properties. It was shown that the Carbon and Woven Glass Fibres in [CWW]6 arrangement was able to withstand loading in the direction of $0^{\circ}$ fabrics. The tensile properties of the composites evaluated is shown in Figure 3. It depicts the influence of biaxial layup in reduced value of tensile strength and tensile modulus which due to failure on in-plane shear direction. The pattern of weave, they are strong at stresses and other directions where stresses untangle them. By packing the fibers pack together, also can provide stronger yarn due to increase in secondary bonding forces between them [52],[53]. This relates to quasi-isotropic layup under study which having an orientation almost similar to weave design. 


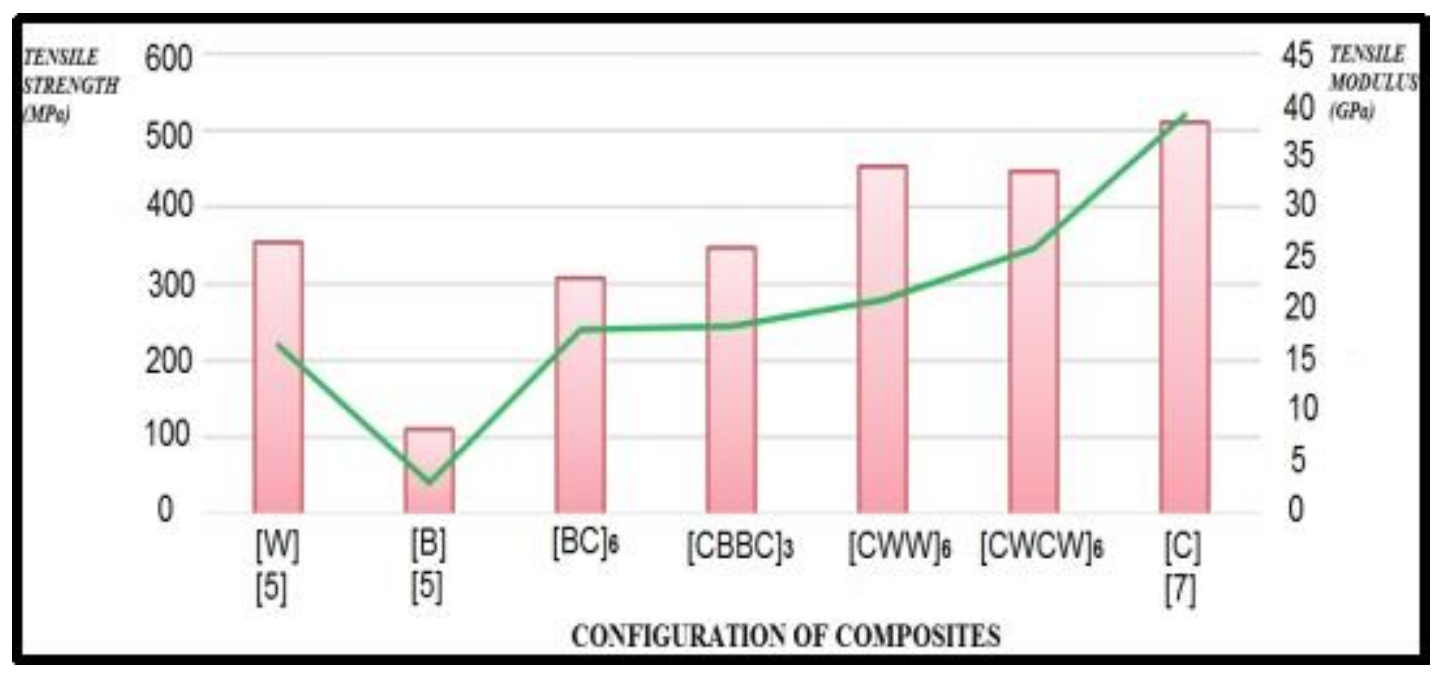

Figure 3. Tensile Properties Obtained from Different Arrangement of Hybrid Composite [51]

In a different study, Wisnom et at (2014) reported the improvement of strain failure up to $20 \%$ for very thin plies UD hybrid composites (S-glass/epoxy and thin carbon/epoxy), meanwhile no significant improvement was observed for thicker laminates [54]. Zhang et al. [55] studied the mechanical behavior of hybrid composites made of carbon/glass reinforcements, and the processing method of wet layup is concluded to be not a best practice for obtaining high-quality laminates. They studied a set of five types of composite arrangement of $[\mathrm{C}]_{8},[\mathrm{C} 2 \mathrm{G} 2]_{\mathrm{s}}$, [CG3]s, [CGCG]s and $[\mathrm{G}]_{8}$ composites, tested under static loading. They concluded on the findings that to enhance the tensile, compressive and flexural strength of plain glass fibre composite, the composition of (50:50) glass/carbon fibre is implemented by positioning the carbon layers at the exterior layup or by arranging at different fibre types alternately. It is further demonstrated that the stacking sequence is insignificant with regards to tensile properties but significantly influence the flexural and compressive properties. Baba et al [56] reported the findings of the mechanical and physical mode of hybrid glass fibre reinforced plastic (GFRP). Hybrid GFRP is formed by three types of glass fibre which are 3D, woven type and chopped type that are mixed with polyester resin as well as a hardener. A parametric study is carried out by varying three parameters namely volume fractions, hybrid GFRP sequence, and single fibre. It was concluded that woven type recorded the highest value of modulus elasticity owing to its stiff and dense geometry as shown in Figure 4. Besides that, the mat interlocking pattern provides advantages for providing anisotropic behaviour [56]. This mechanism improves the fibermatrix interfacial shear strength. 


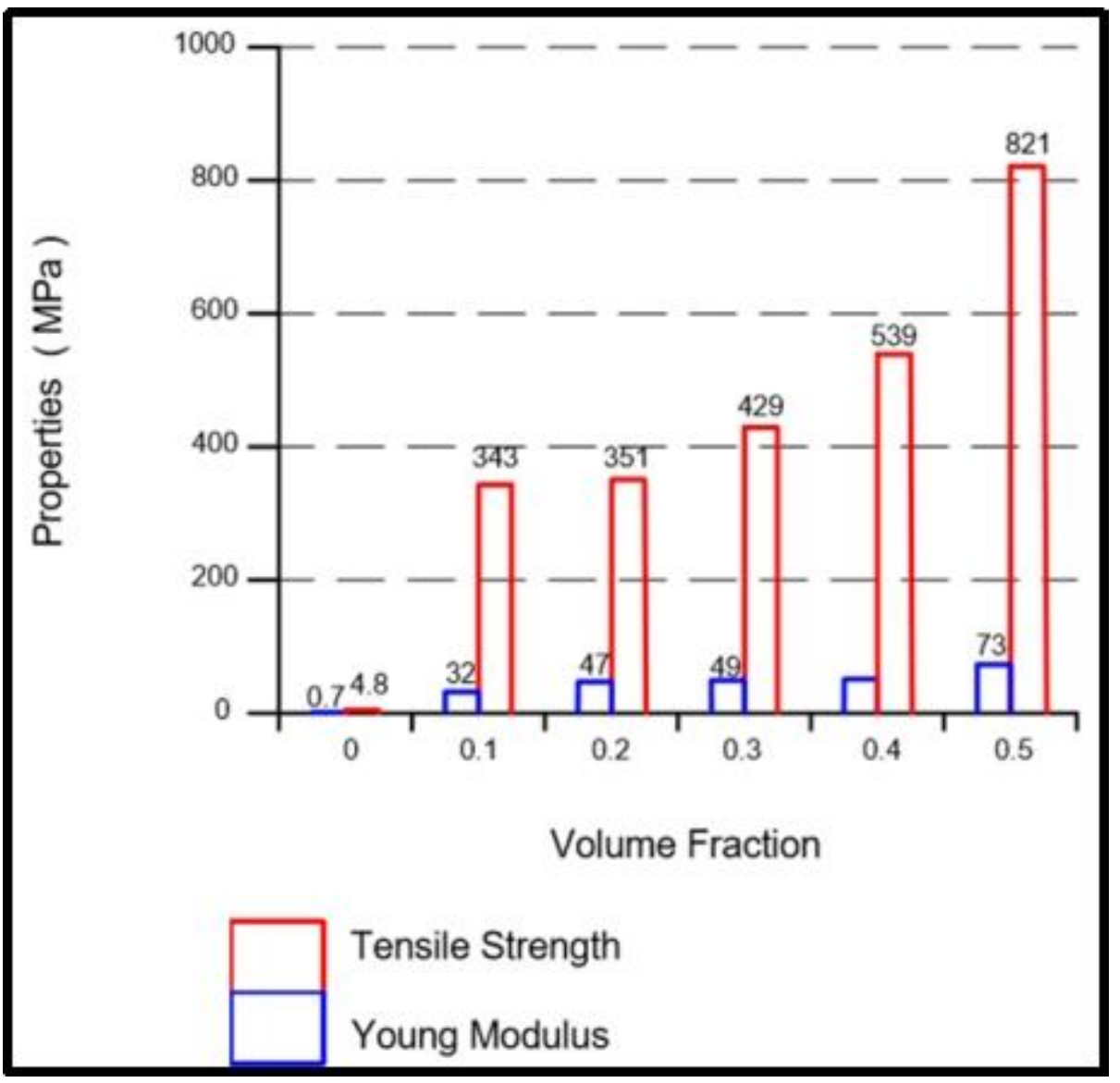

Figure 4 Mechanical Properties of Hybrid Woven GFRP Varying Fibre Volume Fraction [56]

\section{Shear Behaviour of Hybrid C/GFRP}

In real engineering scenario, part or structural component is subjected to multiaxial loading and including shear [1]. Various techniques have been used by scholars to compute shear modulus and shear strength of unidirectional composites. The determination of shear modulus can be predicted with high accuracy via experimental methods such as using the offaxis tensile test and Iosipescu shear test method which are able to produce a perfect shear field on the V-notch region to determine the shear strength [57]. In orthotropic materials, the shear modulus is an independent mechanical property which must be computed for each different material. The typical method of computing this form of modulus is to establish the specimen geometry and the loading system which form a state of pure shear with respect to the principal material directions [47]. The shear stress $(\tau)$ is obtained from the measured load divided by the cross-sectional area in shear. The shear modulus is determined from:

$$
G_{12}=\frac{\tau_{x y}}{\gamma_{x y}}
$$

where the 1-2 subscripts denote to the principal material directions [1].

The off-axis tensile test has been a fundamental technique for characterizing the mechanical response on shear deformation of unidirectional composite materials. In a highly cited paper on an off-axis shear test of composite material [57], a combined theoretical/experimental study was performed to assess the practicality of 10o off-axis tensile test specimen for intralaminar shear loading characterization of unidirectional composites. Strain gauges were attached on the surface of coupons to determine strain across coupon width as well as coupon mid length as well as near end tabs. The specimens are made from Carbon T300/epoxy and S-glass/epoxy for the off-axis shear testing. It was found that the $10^{\circ}$ off-axis tensile test sample is feasible for intralaminar shear characterization. It is suggested that it should be selected as a possible standard test specimen for shear characterization [57].

It is suggested that the use of oblique tabs could provide a more uniform shear displacement field in the specimen [47],[58]. However, Balakrishnan et al. [59] performed the $10^{\circ}$ off-axis test on a unidirectional carbon fibre/epoxy 
composite with straight tabs and reported that more than half of the specimens failed in the gauge section (instead of the gripped section), which suggests that the parasitic shear stresses were negligible [59]. The ASTM standard D 3039-76 proposed the use of tabs that are made of a similar material being tested in order to reduce stress concentrations [60]. Agarwal et al [61] performed a study on the effect of stacking sequence on physical, mechanical and tribological properties of glass carbon hybrid composites. The testing method employed to determine the shear is by using a short beam shear via a universal testing machine (UTM). Intralaminar Shear Strength (ILSS) values obtained are higher for glass/carbon hybrid composites in comparison to glass fabric laminate composites and carbon fabric laminate composites. They observed that better interfacial bonding was attained when carbon fabrics are used together with glass fabrics. It was shown that the percentage amount of fabric reinforcement of glass carbon hybrid composites have a significant effect on the mechanical properties of the composites. Interlaminar shear strength is observed to show an insignificant effect with the increasing amount of fabric reinforcement [61]. Redda and Alene [62] conducted an experimental analysis of bamboo and E-Glass fibre reinforced epoxy hybrid composite to characterize the deformation and behaviour for various loading conditions including shear [62]. The in-plane shear coupon was prepared by off-axis tensile tests of a $\pm 45^{\circ}(+$ $45^{\circ}$ and $-45^{\circ}$ lamina) orientation and produce $2.5 \mathrm{~mm}$ thick composite plate, showing that shear stress increased linearly as the strain increases until the point of ultimate load under shearing load. In a different study by Liang et al. reported [60], a set of epoxy matrix materials reinforced by unidirectional (UD) carbon tapes, as well as satin and twill carbon, weaved fabrics composite were prepared. The experimental results show that fabric reinforced composite exhibits a bit of ductile response in the early phase and shows an improved load bearing ability in the post-yield region as compared to the unidirectional (UD) fibre composite. It is observed that fabric reinforced composites have a prolonged shear stressstrain response with higher nonlinearities compared to unidirectional (UD) FRP and it is capable of absorbing more energy due to higher ultimate stress and strain than unidirectional (UD) composite [60]. Meanwhile, experimental tests of CFRP and GFRP off-axis textile laminates of $\pm 45^{\circ}$ demonstrated highly nonlinear behaviour as compared to their on-axis samples. Both CFRP and GFRP $\pm 45^{\circ}$ specimens exhibited a large deformation nonlinear behaviour which accounts for the strain to failure by up to $35 \%$ and $30 \%$, respectively [63]. Another significant finding of hybrid composite consisting of GFRP/Aramid exhibited that glass fibre reinforcement produces an increase in shear modulus than aramid fibre at the same fibre loading [64]. Moreover, it was reported in different studies that interlaminar shear stresses are responsible for an important failure mode which is delamination that occurs within the hybrid and non-hybrid composites [65],[66].

\section{Flexural Behaviour of Hybrid C/GFRP}

Relative glass to carbon ratios significantly affects the flexural properties. The hybridisation can improve the flexural properties of hybrid composites. Research performed by Raja and Harirao [65] on three-point bending test on hybrid composite glass fibre and carbon fibre performed by using $15 \mathrm{kN}$ capacity universal testing machine, they observed that carbon/glass hybrid laminate with $0^{\circ} / 90^{\circ}$ orientation possess higher shear delamination strength as compared to \pm 450 orientation hybrid laminates [65]. Dong et al. [67] investigated the optimal design of hybrid composites. They concluded that the fibre volume fraction of the glass/epoxy section needs to be higher than the carbon/epoxy section in order to achieve positive hybrid effects [67]. The hybrid effect is significant when the hybrid ratio is small, which may be attributed to the relative position of the GFRP layer(s) with respect to the neutral plane. They formulated a simple mathematical rule to obtain the flexural modulus of the hybrid composites, but the modulus obtained from FEM is higher than the value obtained from experiments [67]. Computation of FEM found to be higher on modulus of elasticity due to the negligence of transverse shear deformation computation on through thickness of shell element used in FEM, while result in the experimental result of deflection is a less than FEM hence decreasing the flexural modulus computed experimentally [3]. Although some investigations on the failure of FRP composites have been carried out, published work concerning the flexural failure mechanisms of unidirectional carbon and glass fibre hybrid FRP composites is limited.

Significant findings have been observed on the mechanical characterization of woven, cross-ply and quasiisotropic made of one constituent of composite material [23],[65],[68]. The relatively low ratio of the compressive to the tensile strength of carbon fibre may be a disadvantage to the use of carbon fibre reinforced polymers (CFRP) composites as structural elements members subjected to compressive and flexural loading [69]. Wonderly et al [70] determined that the compressive to tensile strength ratio of glass fibre reinforced polymer (GFRP) composite was relatively high at 0.73 [70]. This demonstrates the major influence of layup sequence of CFRP and GFRP on the flexural coupon under flexural testing since GFRP possesses a considerably high capability of compressive agility as compared to CFRP. Moreover, Daniel et al. [71] observed that the failure of CF/epoxy composites subjected to compression loading initiated with matrix shear followed by fibre micro-buckling. Hence, this failure mode is expected to play dominant role in the failure mechanism of hybrid C/GFRP. Jesthi et al [72] found that the replacement of glass fibre by carbon fibre produced increment by $62 \%$ in the flexural modulus as compared to pure glass fibre composite, and flexural strain to failure enhanced by $25 \%$. This is fundamentally correct as flexural modulus of CFRP is higher than GFRP [69].In terms of the interlayer hybrid composite, the stacking sequence of fibre distributes in the top or bottom layers is an essential parameter that influences the flexural behavior [24],[67],[69],[73]. It was also observed that flexural properties of hybrid composites could be enhanced as glass fibre positioned in the upper layer and maximum flexural strength could be attained with the carbon layers at the exterior layup [51]. In addition to the layup structure, the mixed ratio plays a critical role in 
determining the flexural properties [74]. Kalantari et al. [75] used the simulation method to optimize the flexural strength, and the application of these optimal stacking sequences contribute to the achievement of a positive hybrid effect.

Other literature includes the interlaminar shear strength of multi-walled carbon nanotube, and carbon fibre reinforced hybrid composite involved short beam shear test 3 points bend loading [76]. It is found that when the transverse shear load experienced by a laminated hybrid composite exceeds the interlaminar shear strength, a delamination failure occur between the layers of reinforcing fibres [76]. The failure mode associated with flexural of composite includes localized damage beneath the loading nose, matrix fretting, compressive kinking and micro damages [77].

\section{CONCLUSION}

The paper presented current study with respect to hybrid composite characterization. Complex deformation is expected for tensile loading, shear loading and bending for hybrid composite. The relation between different compositions of hybrid composite was studied from tensile properties perspective, shear properties characterization and flexural deformation. Reinforced hybrid composite by carbon and glass fibres represent an alternative to conventional metal materials and could find possible applications in modern aircraft for the manufacture of aircraft parts.

\section{ACKNOWLEDGEMENT}

I would like to thank and express gratitude to Faculty of Mechanical Engineering (FKM) and Faculty of Engineering Mechanical and Manufacturing (FTKMP), Universiti Teknikal Malaysia Melaka (UTeM) in offering expertise sharing and technical advice from the academic staff.

\section{REFERENCES}

[1] H. Tan, L. Qin, Z. Jiang, Y. Wu, and B. Ran, “A hybrid deep learning based traffic flow prediction method and its unde[1] B. Harris, "Engineering Composite Materials", Second Edition, London:IOM Communications, 1999.

[2] J. P. Jose, S. K. Malhotra, S. Thomas, K. Joseph, K. Goda, and M. S. Sreekala, "Advances in Polymer Composites: Macro and Microcomposites - State of the Art, New Challenges, and Opportunities," Polymer Composites, vol. 1, pp. 1-16, 2012.

[3] R. M. Jones, "Mechanics of Composite Materials", Second Edition, vol. 102, no. 27. Taylor \& Francis, Inc, 2010.

[4] S. Thomas, "Hybrid Composites," Biocomposites (December) (2002), pp. 315-328

[5] Luca Motoc, D., S. Ferrandiz Bou, and R. Balart Gimeno, "Effects of Fibre Orientation and Content on the Mechanical, Dynamic Mechanical and Thermal Expansion Properties of Multi-Layered Glass/Carbon Fibre-Reinforced Polymer Composites", Journal of Composite Materials, vol 49, no 10, pp. 1211-1221, 2014.

[6] Y. Swolfs, I. Verpoest, and L. Gorbatikh, "Maximising the Hybrid Effect in Unidirectional Hybrid Composites," Mater. Des., vol. 93(January), pp. 39-45, 2016.

[7] R. Thirumalai, D. Prabhakaran, L. Andersen, and C. Malte, "Tensile and Compression Properties of Hybrid Composites - A Comparative Study," Proc. 19th Int. Conf. Compos. Mater. Publ., pp. 1029-1035, 2013.

[8] J. Zhang, K. Chaisombat, S. He, and C. H. Wang, "Hybrid Composite Laminates Reinforced with Glass/Carbon Woven Fabrics for Lightweight Load Bearing Structures,” Mater. Des., vol. 36 (July), pp. 75-80, 2012.

[9] K. S. Pandya, C. Veerraju, and N. K. Naik, "Hybrid composites made of carbon and glass woven fabrics under quasi-static loading," Mater. Des., vol. 32, no. 7, pp. 4094-4099, 2011.

[10] M. Kalantari, C. Dong, and I. J. Davies, "Multi-objective analysis for optimal and robust design of unidirectional glass/carbon fibre reinforced hybrid epoxy composites under flexural loading," Compos. Part B Eng., vol. 84, pp. 130-139, 2016.

[11] Y. Swolfs, "Perspective for fibre-hybrid composites in wind energy applications," Materials (Basel)., vol. 10, no. 11, 2017.

[12] M. M. Davoodi, S. M. Sapuan, D. Ahmad, A. Aidy, A. Khalina, and M. Jonoobi, "Concept selection of car bumper beam with developed hybrid bio-composite material," Mater. Des., vol. 32, no. 10, pp. 4857-4865, 2011.

[13] M. R. Mansor, S. M. Sapuan, E. S. Zainudin, A. A. Nuraini, and A. Hambali, "Hybrid natural and glass fibers reinforced polymer composites material selection using Analytical Hierarchy Process for automotive brake lever design," Mater. Des., vol. 51, pp. 484-492, 2013.

[14] Y. Swolfs, R. M. Mcmeeking, V. P. Rajan, F. W. Zok, and I. Verpoest, "Global load-sharing model for unidirectional hybrid fibre- reinforced composites", Journal of the Mechanics and Physics of Solids, vol. 84, pp. 380-394, 2015.

[15] G. Kretsis, "A Review of the Tensile, Compressive, Flexural and Shear Properties of Hybrid Fibre-Reinforced Plastics," Composites, vol. 18, no. 1, 1987, pp. 13-23, 1987.

[16] E. H. Saidane, D. Scida, M. Assarar, and R. Ayad, "Damage mechanisms assessment of hybrid flax-glass fibre composites using acoustic emission," Compos. Struct., vol. 174, pp. 1-11, 2017.

[17] Z. Zhai, B. Jiang, and D. Drummer, "Characterization of non-linear response of quasi-unidirectional E-glass fabric reinforced polypropylene composites under off-axis tensile loading," Compos. Part B Eng., vol. 148, pp. 180-187, 2018. 
[18] P. Palanethra and V. L. J. A. Guptha, "Experimental Investigation of Stress Concentration Factor in a Unidirectional Carbon / E-Glass Fiber Hybrid Composite," Int J of Metl \& Mat Sci and Eng (IJMMSE), vol. 4, no. 2, pp. 17-24, 2014.

[19] D. Cai, G. Zhou, X. Wang, C. Li, and J. Deng, "Experimental investigation on mechanical properties of unidirectional and woven fabric glass/epoxy composites under off-axis tensile loading," Polym. Test., vol. 58, pp. 142-152, 2017.

[20] Y. Zheng et al., "Tensile response of carbon-aramid hybrid 3D braided composites," Mater. Des., vol. 116, pp. $246-252,2017$.

[21] E. Ameri, L. Laperriere, and G. Lebrun, "Mechanical characterization and optimization of a new unidirectional flax/paper/epoxy composite,” Compos. Part B Eng., vol. 97, pp. 282-291, 2016.

[22] K. Naresh, K. Shankar, R. Velmurugan, and N. K. Gupta, "Statistical analysis of the tensile strength of GFRP, CFRP and hybrid composites," Thin-Walled Struct., vol 126, pp 150-161, 2018

[23] R. Moulart, F. Pierron, S. R. Hallett, and M. R. Wisnom, "Full-Field Strain Measurement and Identification of Composites Moduli at High Strain Rate with the Virtual Fields Method,” Exp. Mech., vol. 51, no. 4, pp.509-536, 2011.

[24] C. Dong and I. J. Davies, "Flexural strength of bidirectional hybrid epoxy carbon fibres," Compos. Part B Eng., vol. 72, pp. 65-71,2015.

[25] G. Vargas and F. Mujika, "Determination of In-plane Shear Strength of Unidirectional Composite Materials Using the Off-axis Three-point Flexure and Off-axis Tensile Tests," J. Compos. Mater., vol. 44, no. 21, pp.2487-2507, 2010. R. Harilal, C. P. Vyasarayani, and M. Ramji, "A linear least squares approach for evaluation of crack tip stress field parameters using DIC,” Opt. Lasers Eng., vol. 75, pp. $\quad 95-102,2015$.

[27] Stepan V. Lomov, Philippe Boisse, Emmanuel de Luycker, Fabrice Morestin, Kristof Vanclooster, "Full-field strain measurements in textile deformability studies", Composites Part A: Applied Science and Manufacturing, Elsevier, vol 39, no 8, pp.1232-1244, 2008

[28] C.-C. Ho, Y.-J. Chang, J.-C. Hsu, C.-L. Kuo, S.-K. Kuo, and G.-H. Lee, "Residual Strain Measurement Using Wire EDM and DIC in Aluminum," Inventions, vol. 1, no. 1, pp $\quad 1-\quad 12,2016$.

[29] R. Harilal and M. Ramji, "Adaptation of Open Source 2D DIC Software Ncorr for Solid Mechanics Applications," 9th Int. Symp. Adv. Sci. Technol. Exp. Mech., 2014.

J. Blaber, B. S. Adair, and A. Antoniou, "A methodology for high resolution digital image $\quad$ correlation in high temperature experiments," Rev. Sci. Instrum., vol. 86, no. 3,2015.

[31] A. T. Nettles, "Basic Mechanics of Laminated Composite Plates," NASA Publication 1351,

[32] A. Bertram and R. Gluge, "Solid mechanics: Theory, modelling, and problems", Springer, 2015.

[33] MIL-HDBK-17-3F, Composite Material Handbook, "Volume 3. Polymer matrix composites: material usage, design and analysis, Department of Defence Handbook, 2002

[34] C. Bouvet, "Mechanics of Aeronautical Solids, Materials and Structures," Wiley-ISTE, 2017.

[35] T. H. K. Kang, W. Kim, S. S. Ha, and D. U. Choi, "Hybrid Effects of Carbon-Glass FRP Sheets in Combination with or without Concrete Beams," Int. J. Concr. Struct. Mater., vol. 8, no. 1, pp. 27-41, 2014.

[36] Y. Swolfs, L. Gorbatikh, and I. Verpoest, "Fibre hybridisation in polymer composites: A review," Compos.Part A Appl. Sci. Manuf., vol. 67, pp. 181-200, 2014.

[37] A. Manalo, H. Mutsuyoshi, and T. Matsui, "Testing and characterization of thick hybrid fibre composites laminates," Int. J. Mech. Sci., vol. 63, no. 1, pp. 99-109, 2012.

[38] S.-J. Park, "Carbon Fibers", Springer Series in Materials Science 210, 2015

[39] H. Rahmani, S. H. M. Najafi, A. Ashori, and M. Golriz, "Elastic properties of carbon fibre-reinforced epoxy composites," Polymers \& Polymer Composites, vol. 23, no. 7, pp. 475-481, 2015.

[40] O. Bitkina, J. Lee, and E. Darlington, "Experimental Study of the Effect of Disorientation Angle on the Deformation of Carbon Composite Plates," Materials Science （Medziagotyra), vol. 22, no. 2, pp. ～285-289, 2016.

[41] Myer Kutz, "Handbook of Materials Selection", Wiley, 2005.

[42] Autar K. Kaw, "Mechanics of Composite Materials", Taylor \& Francis Group, LLC, 2006.

[43] U. A. Khashaba, "In-plane shear properties of cross-ply composite laminates with different off-axis angles," Compos. Struct., vol. 65, no. 2, pp. 167-177, 2004.

[44] T. P. Sathishkumar, S. Satheeshkumar, and J. Naveen, "Glass fiber-reinforced polymer composites - A review," J. Reinf. Plast. Compos., vol. 33, no. 13, pp. 1258-1275, 2014.

[45] Myer Kutz, "Mechanical Engineers' Handbook", Fourth Edi., JohnWiley \& Sons, Inc., 2015.

[46] G. Odegard and M. Kumosa, "Determination of shear strength of unidirectional composite materials with the Iosipescu and $10^{\circ}$ off-axis shear tests," Compos. Sci. Technol., vol. 60, no. 16, pp. 2917-2943, 2000.

[47] J. C. Xavier, N. M. Garrido, M. Oliveira, J. L. Morais, P. P. Camanho, and F. Pierron, "A comparison between the Iosipescu and off-axis shear test methods for the characterization of Pinus Pinaster Ait," Compos. Part A Appl. Sci. Manuf., vol. 35, no. 7-8, pp. 827-840, 2004.

[48] R. T. D. Prabhakaran, T. L. Andersen, C. M. Markussen, B. Madsen, and H. Lilholt, "Tensile and Compression Properties of Hybrid Composites - A Comparative Study,” 19th Int. Conf. Compos. Mater. (ICCM 19), pp. 1029-1035, 2013.

[49] M. Quanjin, M. R. M. Rejab, J. Kaige, M. S. Idris, and M. N. Harith, "Filament winding technique, experiment and simulation analysis on tubular structure," IOP Conf. Ser. Mater. Sci. Eng., vol. 342, no. 1, 2018.

[50] N. Minsch, F. H. Herrmann, T. Gereke, A. Nocke, and C. Cherif, "Analysis of Filament Winding Processes and Potential Equipment Technologies," Procedia CIRP, vol. 66, pp. 125-130, 2017.

[51] M. M. W. Irina, A. I. Azmi, C. L. Tan, C. C. Lee, and A. N. M. Khalil, "Evaluation of Mechanical Properties of Hybrid Fiber Reinforced Polymer Composites and Their Architecture," Procedia Manuf., vol. 2, pp. 236-240, 2015.

[52] T. Bergmann, S. Heimbs, and M. Maier, "Mechanical properties and energy absorption capability of woven fabric composites under $\pm 45^{\circ}$ off-axis tension," Compos. Struct., vol. 125, pp. 362-373, 2015.

[53] M. Klasztorny, D. Nycz, and R. Labuda, "Modelling, simulation and experimental validation of bend tests on GFRP laminate beam and plate specimens," Compos. Struct., vol. 184, pp. 604-612, 2018.

[54] M. R. Wisnom, G. Czel, Y. Swolfs, M. Jalalvand, L. Gorbatikh, and I. Verpoest, "Hybrid effects in thin ply carbon/glass unidirectional laminates: Accurate experimental determination and prediction," Compos. Part A Appl. Sci. Manuf., vol. 88, pp. 131-139, 2016. 
[55] J. Zhang, K. Chaisombat, S. He, and C. H. Wang, "Hybrid composite laminates reinforced with glass/carbon woven fabrics for lightweight load bearing structures," Mater. Des., vol. 36, pp. 75-80, 2012.

[56] N. B. Baba, A. S. Suhaimi, M. A. Mohd Amin, and A. Mohd, "Study on Mechanical and Physical Behaviour of Hybrid GFRP," Adv. Mater. Sci. Eng., vol 2015, pp 1-7, 2015.

[57] C. C. Chamis and J. H. Sinclair, "10 $0^{\circ}$ Off-Axis Tensile Test for Intralaminar Shear Characterization of Fiber Composites," NASA Tech. Note D-8215, April 1976.

[58] F. Pierron and a Vautrin, "The $10^{\circ}$ circ off-axis tensile test: A critical approach," Compos. Sci. Technol., vol. 56, no. 4, pp. 483-488, 1996.

[59] M. K. M. V. Balakrishnan, B. Bansal, "Biaxial Testing of Unidirectional Carbon-Epoxy Composite Using Biaxial Iosipescu Test Fixture,” J. Compos. Mater., vol. 31, no. 5, pp. 468-508, 1997.

[60] Y. Liang, H. Wang, and X. Gu, "In-plane shear response of unidirectional fiber reinforced and fabric reinforced carbon/epoxy composites," Polym. Test., vol. 32, no. 3, pp. 594-601, 2013.

[61] G. Agarwal, A. Patnaik, R. Kumar Sharma, and J. Agarwal, "Effect of stacking sequence on physical, mechanical and tribological properties of glass-carbon hybrid composites," Friction, vol. 2, no. 4, pp. 354-364, 2014.

[62] Daniel Redda and Abiy Alene, "Experimental Analysis of Bamboo and E-Glass Fiber Reinforced Epoxy Hybrid Composite," J. Mater. Sci. Eng. B, vol. 6, no. 3, pp. 153-160, 2016.

[63] H. Ullah, A. R. Harland, R. Blenkinsopp, T. Lucas, D. Price, and V. V. Silberschmidt, "Analysis of Nonlinear Shear Deformations in CFRP and GFRP Textile Laminates," Appl. Mech. Mater., vol. 70, pp. 363-368, 2011.

[64] A. Desai, M. L. Auad, H. Shen, and S. Nutt, "Mechanical Behavior of Hybrid Composite Phenolic Foam," J. Cell. Plast., vol. 44, 2008.

[65] M. N. Guru Raja and A. N. Harirao, "Interlaminar Shear Strength of Cross Ply and Angle Ply Carbon/Glass Hybrid Composites," Int. J. Compos. Mater., vol. 3, no. 6, pp. 141-144, 2013.

[66] K. Gliesche, T. Hübner, and H. Orawetz, "Investigations of in-plane shear properties of $\pm 45^{\circ}$-carbon/epoxy composites using tensile testing and optical deformation analysis," Compos. Sci. Technol., vol. 65, no. 2, pp. 163-171, 2005.

[67] C. Dong and I. J. Davies, "Optimal design for the flexural behaviour of glass and carbon fibre reinforced polymer hybrid composites,” Mater. Des., vol. 37, pp. 450-457, 2012.

[68] A. A. Eremin, E. V. Glushkov, N. V. Glushkova, and R. Lammering, "Evaluation of effective elastic properties of layered composite fiber-reinforced plastic plates by piezoelectrically induced guided waves and laser Doppler vibrometry," Compos. Struct., vol. 125, pp. 449-458, 2015.

[69] C. Dong, Sudarisman, and I. J. Davies, "Flexural properties of e glass and TR50S carbon fiber reinforced epoxy hybrid composites," J. Mater. Eng. Perform., vol. 22, no. 1, pp. 41-49, 2013.

[70] C. Wonderly, J. Grenestedt, G. Fernlund, and E. Cepus, "Comparison of mechanical properties of glass fiber/vinyl ester and carbon fiber/vinyl ester composites,” Compos. Part B Eng., vol. 36, no. 5, pp. 417-426, 2005.

[71] I. M. Daniel, H. M. Hsiao, and S. C. Wooh, "Failure mechanisms in thick composites under compressive loading," Compos. Part B Eng., vol. 27, no. 6., pp. 543-552, 1996.

[72] D. K. Jesthi, P. Mandal, A. K. Rout, and R. K. Nayak, "Effect of carbon/glass fiber symmetric inter-ply sequence on mechanical properties of polymer matrix composites," Procedia Manuf., vol. 20, pp. 530-535, 2018.

[73] C. Dong, M. Kalantari, and I. J. Davies, "Robustness for unidirectional carbon/glass fibre reinforced hybrid epoxy composites under flexural loading," Compos. Struct., vol. 128, pp. 354-362, 2015.

[74] H. Ikbal, Q. Wang, A. Azzam, and W. Li, "Effect of Hybrid Ratio and Laminate Geometry on Compressive Properties of Carbon / Glass Hybrid Composites," Fibers Polym, vol. 17, no. 1, pp. 117-129, 2016.

[75] M. Kalantari, C. Dong, and I. J. Davies, "Numerical investigation of the hybridisation mechanism in fibre reinforced hybrid composites subjected to flexural load," Compos. $\quad$ Part B Eng., vol. 102, pp. 100-111, 2016.

[76] K. C. Shekar, B. A. Prasad, and N. E. Prasad, "Interlaminar Shear Strength of Multi- walled Carbon Nanotube and Carbon Fiber Reinforced, Epoxy - Matrix Hybrid Composite,” Procedia Mater. Sci., vol. 6, pp. 1336-1343, 2014.

[77] A. I. Selmy, A. R. Elsesi, N. A. Azab, and M. A. Abd El- Baky, "Interlaminar shear behavior of unidirectional glass fiber (U)/random glass fiber (R)/epoxy hybrid and non- $\quad$ hybrid composite laminates," Compos. Part B Eng., vol. 43, no. 4, pp. 1714-1719, 2012. 